\title{
Detection of Circulating Tumor Cells and Microbial DNA Fragments in Stage III Colorectal Cancer Patients under Three versus Six Months of Adjuvant Treatment
}

\author{
Asimina Koulouridi ${ }^{1,2,+}$, Ippokratis Messaritakis ${ }^{1, *,+}+\mathbb{D}$, Emmanouil Theodorakis ${ }^{1}$, Maria Chondrozoumaki ${ }^{1}$, \\ Maria Sfakianaki ${ }^{1}$, Nikolaos Gouvas ${ }^{3}\left(\mathbb{D}\right.$, John Tsiaoussis ${ }^{4}\left(\mathbb{D}\right.$, Dimitrios Mavroudis ${ }^{1,2}$, Maria Tzardi ${ }^{5}$ and \\ John Souglakos ${ }^{1,2}$
}

Citation: Koulouridi, A.;

Messaritakis, I.; Theodorakis, E.;

Chondrozoumaki, M.; Sfakianaki, M.;

Gouvas, N.; Tsiaoussis, J.;

Mavroudis, D.; Tzardi, M.;

Souglakos, J. Detection of Circulating

Tumor Cells and Microbial DNA

Fragments in Stage III Colorectal

Cancer Patients under Three versus Six Months of Adjuvant Treatment.

Cancers 2021, 13, 3552.

https://doi.org/

10.3390/cancers13143552

Academic Editor: Anders Jakobsen

Received: 16 June 2021

Accepted: 14 July 2021

Published: 15 July 2021

Publisher's Note: MDPI stays neutral with regard to jurisdictional claims in published maps and institutional affiliations.

Copyright: (c) 2021 by the authors. Licensee MDPI, Basel, Switzerland. This article is an open access article distributed under the terms and conditions of the Creative Commons Attribution (CC BY) license (https:/ / creativecommons.org/licenses/by/ $4.0 /)$.
1 Laboratory of Translational Oncology, Medical School, University of Crete, 70013 Heraklion, Greece; medp2011871@med.uoc.gr (A.K.); bio2885@edu.biology.uoc.gr (E.T.); med3425@edu.med.uoc.gr (M.C.); msfakianak@uoc.gr (M.S.); mavroudis@uoc.gr (D.M.); souglak@uoc.gr (J.S.)

2 Department of Medical Oncology, University General Hospital of Heraklion, 70013 Heraklion, Greece

3 Medical School, University of Cyprus, 20537 Nicosia, Cyprus; gouvas.nikolaos@ucy.ac.cy

Department of Anatomy, School of Medicine, University of Crete, 70013 Heraklion, Greece; tsiaoussis@uoc.gr

5 Laboratory of Pathology, Medical School, University of Crete, 70013 Heraklion, Greece; tzardi@med.uoc.gr

* Correspondence: imessar@edu.med.uoc.gr; Tel.: +30-2810-394926

+ Asimina Koulouridi and Ippokratis Messaritakis equally contributed to this work.

Simple Summary: Duration of adjuvant therapy in stage III CRC is now under re-evaluation. The aim of the current study was the detection of microbial DNA that could be originated from the intestine (16S rRNA, E. coli, B. fragilis and C. albicans) and the detection of CTCs during treatment with FOLFOX or CAPOX, in stage III CRC patients. CTCs were significantly decreased after 3 months of treatment, whereas 6 months resulted to their increase again. A significant increase of CTCs was demonstrated in patients under FOLFOX for 6 months. A significant correlation was demonstrated following microbial DNAs and both CTCs detection at baseline and CTCs increase, between baseline and 3 months of treatment. The results provide additional evidence of non-inferiority of 3 over 6 months of treatment, mainly in patients under CAPOX.

Abstract: Oxaliplatin-fluoropyrimidine combination therapy is the gold standard treatment for patients with stage III colorectal cancer (CRC); however, treatment duration is now under re-evaluation. The aim of the study was the evaluation of the non-inferiority of three over six months treatment with FOLFOX or CAPOX, in stage III CRC patients. Peripheral blood samples from 121 patients were collected, at three time points during treatment and evaluated for circulating tumor cells (CTCs) and microbial DNA detection (16S rRNA, Escherichia coli, Bacteroides fragilis, Candida albicans). Of all patients, $41.3 \%$ and $58.7 \%$ were treated with FOLFOX and CAPOX, respectively. CTCs were significantly decreased and increased after three and six months of treatment, respectively. CAPOX tends to reduce the CTCs after 3 months, whereas there is a statistically significant increase of CTCs in patients under FOLFOX after 6 months. A significant correlation was demonstrated between microbial DNA detection and both CTCs detection at baseline and CTCs increase between baseline and three months of treatment. To conclude, the current study provides additional evidence of non-inferiority of three over 6 months of treatment, mainly in patients under CAPOX.

Keywords: colorectal cancer; stage III; adjuvant chemotherapy; circulating tumor cells; microbial DNA; three vs. six months adjuvant treatment

\section{Introduction}

Colorectal cancer $(\mathrm{CRC})$ remains the third most frequent cancer type worldwide and a common reason of mortality because of solid tumors [1]. Stage III CRC patients have up to $60 \%$ 5-years overall survival (OS) and adjuvant chemotherapy aims to raise this percentage 
and prolong both the OS and the disease-free survival (DFS) [2]. The oxaliplatin- fluoropyrimidine combination chemotherapy, Fluorouracil-leucovorin-oxaliplatin (FOLFOX) or capecitabine-oxaliplatin (CAPOX) for 6 months was the gold standard treatment for such a group of patients $[2,3]$. However, oxaliplatin may lead to adverse effects, and especially neuropathy [4]. Usually, neuropathy starts soon after the regimen infusion and it takes few days to resolve. Sometimes, peripheral neuropathy can remain for longer periods (up to 3-5 years) lowering the patients' quality of life [5]. Moreover, the total cost of adjuvant therapy for stage III CRC patients in Europe would be reduced for a half a billion by using three months of CAPOX instead of 6 months of FOLFOX [5]. IDEA collaboration was an attempt to reduce the time of adjuvant treatment [6]. The primary endpoint of IDEA was the non-inferiority of using three versus 6 months of adjuvant treatment, by comparing 3 -year DFS. In a total of 12,834 patients who received three months or 6 months of adjuvant chemotherapy, the non-inferiority statistical margin was not reached. However, it was shown that the use of CAPOX for three months, especially in low-risk patients could be as effective as 6 months treatment [6,7]. However, concerning OS, despite the non-inferiority of three months of adjuvant treatment was not achieved, the difference of $0.4 \%$ that there was in 5-year OS between the two different treatment durations, should be under clinical evaluation [8].

Liquid biopsy is playing a new, crucial role on the detection and monitoring of different cancer types. Its role is important for early diagnosis, treatment selection, as a prognostic tool or for monitoring treatment efficacy [9]. Circulating tumor cells (CTCs) escape to bloodstream from the tumor and are implicated in the procedure of micrometastasis [10]. Various technologies have been used for their detection: immunocytological, molecular and functional assays [11]. It has been shown that CTCs have a prognostic and predictive value for patients with CRC [12-15].

Carcinoembryonic antigen (CEA) is the most frequently used marker for the recognition of tumors cells in CRC. Immunohistochemistry has been used CEA, for years as a characteristic of CRC tumors, and has been validated through this time [16,17]. Molecular methods have also been developed. Our group has previously developed such a reproducible method for the detection of CEA-like cellular adhesion molecule 5 (CEACAM5) mRNA positive CTCs in patients with CRC $[12,18]$, and such a detection revealed their prognostic value [12].

Gut microbiota seems to play an important role to human health. The intestinal dysbiosis, is linked to various immune and metabolic conditions [19]. Dysbiosis is one of the mechanisms that lead to microbial translocation, which refers to the passage of intestinal microbes into the bloodstream. Not only these microbes, but also their products (lipopeptides, endotoxins, peptidoglycan and nucleid acids, could be detected in the blood [20]. These microbial fragments can be detected by several molecular techniques [21-25]. As it has been reported previously, the microbial DNA detection in the blood of such patients highlights the involvement of such microbes in CRC tumorigenesis, disease progression/recurrence, and overall survival [21-25].

With this prospective, single institution study, we aimed to the detection and comparison of CEACAM5-positive CTCs with microbial DNA detection which could be originated from the intestine, in the blood of patients with stage III CRC under three versus 6 months of chemotherapy. To our knowledge, this is the first time that laboratory parameters are analyzed and compared in an attempt to prove non-inferiority of three vs 6 months of adjuvant treatment.

\section{Materials and Methods}

\subsection{Patients Enrollment and Ethics Approval}

In total, 121 patients with stage III CRC were included in the present, single-centered study. Inclusion criteria involved the age $>18$ years old of the enrolled patients, presence of stage III CRC adenocarcinoma following curative surgical resection and adjuvant therapy initiation with FOLFOX or CAPOX within 8 weeks following surgery. Patients with a 
presence of additional solid tumors were excluded from the study. All patients enrolled are patients of the Department of Medical Oncology, University Hospital of Heraklion.

\subsection{Blood Sampling}

Peripheral blood ( $15 \mathrm{~mL}$ in EDTA) was collected at the middle-of-vein puncture. To avoid contamination with skin epithelial cells, the first $5 \mathrm{~mL}$ of blood were discarded.

Peripheral blood mononuclear cells (PBMCs) were isolated by Ficoll-Hypaque ( $\mathrm{d}=1077 \mathrm{~g} / \mathrm{mL}$; Sigma-Aldrich, $\mathrm{GmbH}$, Taufkirchen, Germany) gradient density centrifugation at $1800 \mathrm{rpm}$, for $30 \mathrm{~min}$. Slide cytospins, RNA extraction and genomic DNA isolation were prepared as previously described [12,14,25-27].

\subsection{Double Immunofluorescence Assay (IFAT)}

Cells that express CEACAM5 but not CD45 which recognizes hematopoietic cells (CEACAM5+/CD45-) where considered as positive CTCs. CEACAM5 was detected using the FITC conjugated monoclonal antibody against CEACAM5 (anti-mouse: Abcam, Cambridge, UK) and CD45 (anti-rabbit: Common Leukocyte Antigen; Santa Cruz, CA, USA) was labelled with Alexa 555 (Molecular Probes, Invitrogen, Rockford, IL, USA). In brief, aliquots of $1 \times 10^{6}$ PBMCs were cytocentrifuged on microscope slides (at $2000 \mathrm{rpm}$ for $2 \mathrm{~min}$ ). Cytospins were air dried and stored at $-80^{\circ} \mathrm{C}$, until use. One slide per patient was analyzed at each time point. Prior staining, PBMCs were fixed for $20 \mathrm{~min}$, in ice-cold acetone:methanol 9:1 $(v / v)$. Incubation time was $1 \mathrm{~h}$ for all antibodies. Additionally, DAPI-antifade (Molecular Probes) was added to each sample to obtain nuclear staining. Slides were analyzed under a fluorescence microscope (Leica DM 2500, Heidelberg, Germany). Results are expressed as number of CTCs $/ 10^{6}$ PBMCs.

\subsection{Reverse Transcription-Quantitative PCR (RT-qPCR)}

The reverse transcription and the qPCR conditions were performed as previously described [12,14]. In brief, the NanoDrop (Thermo Fisher Scientific, Wilmington, DE, USA) equipment was used to measure RNA concentration. $\beta$-actin gene amplification was used for RNA integrity verification. RNA from the Lovo (colorectal cell line) and ARH-77 (leukemic cell line) were used as positive and negative controls, respectively. ABI Prism 7900HT Sequence Detection System (Applied Biosystems, Waltham, Massachusetts, USA) was used for gene expression quantification. All experimental analysis run in triplicates. An external calibration curve obtained using external standard cDNAs was used for quantification [12,14]. In brief, RNA from $1 \times 10^{6}$ Lovo cells was used for cDNA synthesis of Lovo cells RNA serial dilutions $\left(1-10^{5}\right)$ and was analyzed in each run. By plotting the number of Lovo cells that correspond to each external standard cDNA vs the value of its quantification cycle, the calibration curve was created. The number of circulating CEACAM5mRNA+cells for all patients' samples was expressed as cell equivalents $/ 5 \mu \mathrm{g}$ of total RNA, based on the external standard calibration curve. The limit of detection (LOD) of the assay was found to correspond to 0.7 Lovo cell equivalents $/ 5 \mu \mathrm{g}$ of RNA ( $\mathrm{LOD}=3.3 \mathrm{SD} /$ slope, where SD is the standard deviation of the quantification cycle for 1 Lovo cell equivalent) [12]. Analysis was performed using the SDS 2.3 software.

\subsection{Microbial DNA Amplification by PCR}

DNA isolation from the whole blood collected before the initiation of adjuvant treatment was done with the QIAamp DNA Blood Mini kit (QIAGEN, Hilden, Germany) following the manufacturer's instructions. The NanoDrop ND-1000 v3.3 (Thermo Fisher Scientific, Rockford, IL, USA) equipment was used for DNA quantification. All materials and conditions for each gene target involved in the present study have been previously described by our group [25]. In brief, three primer pairs were used to detect bacterial genomic DNA encoding 16S rRNA; glutamine synthase of Bacteroides fragilis; $\beta$-galactosidase gene of most Escherichia coli and one primer pair to detect 5.8S rRNA found in Candida albicans; the human glyceraldehyde phospho-dehydrogenase (GAPDH) was used as a reference 
gene to verify DNA integrity of the samples. 16S rRNA was used as a reference in the detection of bacterial (only) DNA in the blood samples.

\subsection{Study Design and Statistical Analysis}

The current study is a prospective study, investigating the detection of CEACAM5 and CEACAM5mRNA in CTCs and of microbial DNA fragments in the blood of CRC patients. The experiments and the evaluation of results were done blindly to patients data. Statistical analysis was done under the SPSS v. 26 environment (IBM Corp. Armonk, New York, USA, as previously described [28]. Statistical significance was set by the user at $p=0.05$.

\section{Results}

\subsection{Patient's Characteristics}

The patients' characteristics are listed in Table 1 . In brief, 121 patients were included in the study. Patients median age was 62 years (range: 37-83 years), 73 (60.3\%) were males, 112 $(92.6 \%)$ had a colon/sigmoid tumor location, $28(23.1 \%)$ had tumors of the right colon, 99 $(85.3 \%)$ were diagnosed with adenocarcinoma and $71(58.7 \%)$ received CAPOX. Moreover, $9(7.4 \%)$ and $41(33.9 \%)$ patients were enrolled in the FOLFOX regimen for 3 and 6 months respectively, whereas $28(23.1 \%)$ and $43(35.6 \%)$ patients were enrolled in the CAPOX regimen for 3 and 6 months respectively. For patients enrolled in the 6 months treatment administration, CTC counts are also available at three months, during treatment. PS-ECOG (Performance Status according to the Eastern Cooperative Oncology Group) for all patients, but one, $0-1$. Moreover, in total 29 (24\%) patients relapsed (Table 1 and Table S1) following treatment completion, 17 (58.6\%) of which treated for 6 months (Table 1 and Table S1).

Table 1. Total number of patients, gender, chosen treatments and number of patients at each time point.

\begin{tabular}{|c|c|c|}
\hline Characteristics & Frequency $(n=121)$ & $\%$ \\
\hline Age (range) & $62(37-83)$ & \\
\hline$<70$ & 83 & 68.9 \\
\hline$\geq 70$ & 38 & 31.4 \\
\hline \multicolumn{3}{|l|}{ Gender } \\
\hline Male & 73 & 60.3 \\
\hline Female & 48 & 39.7 \\
\hline \multicolumn{3}{|l|}{ PS (ECOG) } \\
\hline $0-1$ & 120 & 99.2 \\
\hline$\geq 2$ & 1 & 0.8 \\
\hline \multicolumn{3}{|l|}{ Surgery } \\
\hline Yes & 121 & 100 \\
\hline No & 0 & 0.0 \\
\hline \multicolumn{3}{|l|}{ Location } \\
\hline Colon/Sigmoid & 112 & 92.6 \\
\hline Rectum & 9 & 7.4 \\
\hline \multicolumn{3}{|l|}{ Right/Left site } \\
\hline Right colon & 28 & 23.1 \\
\hline Left colon & 93 & 76.9 \\
\hline \multicolumn{3}{|l|}{ Histology } \\
\hline Adenocarcinoma & 99 & 85.3 \\
\hline Mucinous & 17 & 14.7 \\
\hline Unknown & 5 & \\
\hline \multicolumn{3}{|l|}{ Regimen } \\
\hline FOLFOX & 50 & 41.3 \\
\hline CAPOX & 71 & 58.7 \\
\hline \multicolumn{3}{|l|}{ Treatment Duration } \\
\hline 3 months & 37 & 30.6 \\
\hline 6 months & 84 & 69.4 \\
\hline
\end{tabular}


Table 1. Cont

\begin{tabular}{ccc}
\hline Characteristics & Frequency $(\boldsymbol{n = 1 2 1 )}$ & \% \\
\hline Regimen and Duration & 9 & 7.4 \\
FOLFOX-3 months & 41 & 33.9 \\
FOLFOX-6 months & 28 & 23.1 \\
CAPOX-3 months & 43 & 35.6 \\
CAPOX-6 months & & \\
\hline
\end{tabular}

\subsection{Detection of CTCs}

\subsubsection{Double Immunofluorescence Assay (IFAT)}

Table 2 and Table S1 demonstrate the results regarding the CTCs detection using IFAT, at all three time points. At the time of the analysis, not all patients have completed their 3- or 6-months treatment administration. Hence, in total 121 samples were available at baseline; 69 patients at 3 months and 54 patients at 6 months. Only CEACAM5+/CD45cells were considered as CTCs (Figure 1). As it was observed, positivity was almost at the same level, for all three time points (baseline: 45\%; 3 months: 44.9\%; 6 months: 44.4\%) (Table 2 and Table S1). However, between baseline and three months of treatment, the absolute number of CTCs was significantly decreased [median: 3 (range: 1-119) vs. median: 1 (range: $1-6) ; p<0.001$ ) (Table 2 and Table S1). Additionally, a significant increase was observed between 3 and 6 months of treatment, in the absolute number of CTCs [median: 1 (range: $1-6)$ vs. median: 2 (range: $1-134) ; p<0.001$ ) (Table 2 and Table S1).

Table 2. Number of CTCs, at all three different time points, during treatment.

\begin{tabular}{|c|c|c|c|c|c|}
\hline \multirow{2}{*}{ Timepoint } & \multicolumn{3}{|c|}{ Immunofluorescence (IFAT) } & \multicolumn{2}{|c|}{ RT-qPCR } \\
\hline & Pos/Neg & No & $\begin{array}{c}\text { Median CTC No } \\
\text { (Range) }\end{array}$ & No $(\%)$ & $\begin{array}{c}\text { Median Copy } \\
\text { Number (Range) }\end{array}$ \\
\hline Baseline & $\begin{array}{l}\text { Pos } \\
\text { Neg }\end{array}$ & $\begin{array}{l}55(45 \%) \\
66(55 \%)\end{array}$ & $3(1-119)$ & $\begin{array}{c}46(38.3 \%)^{*} \\
74(61.7 \%)\end{array}$ & $1.1(0.71-6.7)$ \\
\hline 3 months & $\begin{array}{l}\text { Pos } \\
\text { Neg }\end{array}$ & $\begin{array}{l}31(44.9 \%) \\
38(55.1 \%)\end{array}$ & $1(1-6) *$ & $\begin{array}{c}24(34.8 \%)^{*} \\
45(65.2 \%)\end{array}$ & $1.1(0.75-2.4)$ \\
\hline 6 months & $\begin{array}{l}\mathrm{Pos} \\
\mathrm{Neg}\end{array}$ & $\begin{array}{l}24(44.4 \%) \\
30(55.6 \%)\end{array}$ & $2(1-134) *$ & $\begin{array}{c}23(42.6 \%) \\
31(57.4 \%)\end{array}$ & $1.2(0.71-12.33)$ \\
\hline
\end{tabular}

CEACAM5

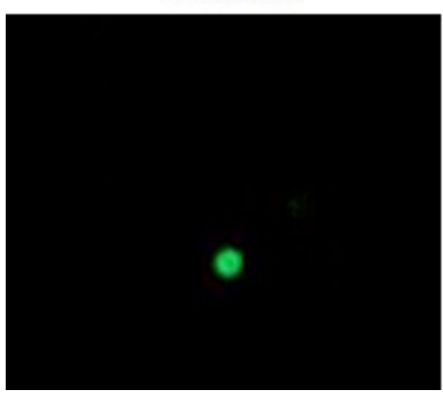

CD45

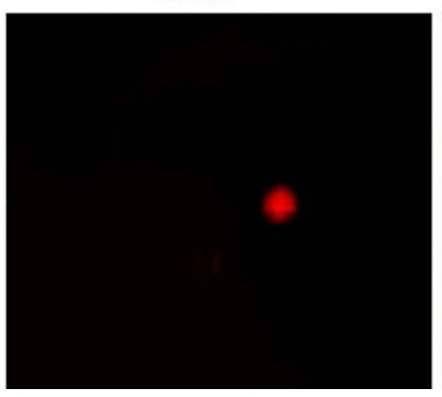

DAPI

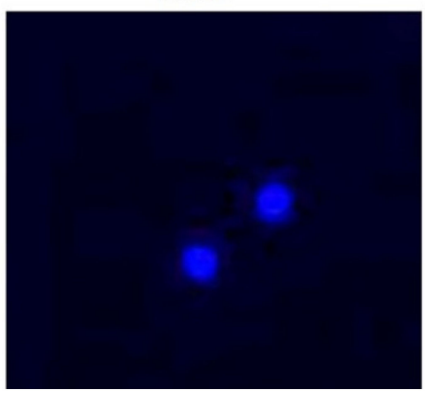

Merge

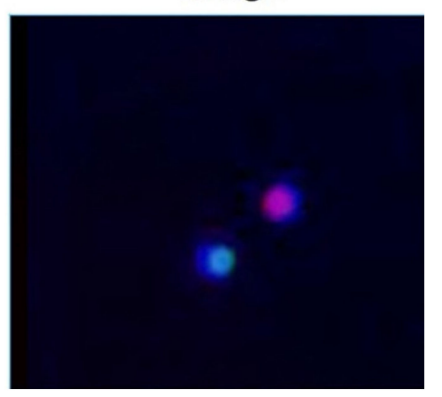

Figure 1. Representative figures taken after double immunofluorescence staining (x40 magnification). As a circulating tumor cell (CTC) was considered a cell that is CEACAM5-positive and CD45-negative. Two cells are presented here: A CTC which expresses CEACAM5 (FITC-green) but not CD45 and a hemopoietic cell which expresses CD45 (Alexa 555-red) but not CEACAM5.

Moreover, the changes in the detection of CTCs were evaluated during treatment. As it was observed, of those patients with CEACAM5-positive cells at baseline, 27.5\% had detectable CEACAM5-positive cells after three months of treatment, whereas $20.3 \%$ 
of patients eliminated their CTCs (Table 3 and Table S1). Of those patients with undetectable CTCs, $33.3 \%$ and $18.8 \%$ remained negative or became positive, respectively (Table 3 and Table S1). Between baseline and 6 months of treatment, $22.2 \%, 5.6 \%, 50 \%$ and $22.2 \%$ remained positive, eliminated their CTCs, remained negative or became positive, respectively (Table 3 and Table S1). There was a significantly greater elimination of CTCs in patients under 3 vs 6 months of treatment ( $p=0.044$, Table 3). Moreover, as it was demonstrated, $57.1 \%, 14.3 \% 14.3 \%$ and $14.3 \%$ of the patients had detectable CTCs both at 3 and 6 months of treatment (remained positive), had detectable CTCs at 3 months but no CTCs were detected at 6 months of treatment (eliminated their cells), had undetectable CTCs at both time-points (remained negative) or had undetectable CTCs at 3 months but detectable CTCs at 6 months of treatment (became positive) (Table 3 and Table S1).

Table 3. Changes in the detection and number of CTCs at during chemotherapy.

\begin{tabular}{cccc}
\hline Detection of CTCs & Baseline-3 Months & Baseline-6 Months & 3 months-6 Months \\
\hline$+/+$ & $27.5 \%$ & $22.2 \%$ & $57.1 \%$ \\
$+/-$ & $20.3 \% *$ & $5.6 \%$ & $14.3 \%$ \\
$-/-$ & $33.3 \%$ & $50 \%$ & $14.3 \%$ \\
$-/+$ & $18.8 \%$ & $22.2 \%$ & $14.3 \%$ \\
\hline Absolute No of & Baseline-3 Months & Baseline-6 Months & 3 months-6 Months \\
CTCs & & & $42.9 \%$ \\
Increased & $23.2 \%$ & $29.6 \%$ & $23.8 \%$ \\
Decreased & $37.7 \%$ & $14.8 \%$ & $33.3 \%$ \\
Stable & $39.1 \%$ & $55.6 \%$ &
\end{tabular}

In the means of the absolute number of CTCs, $23.2 \%$ and $37.7 \%$ of the patients increased and decreased their CTCs, respectively, whereas in $39.1 \%$ of the patients, the number of their CTCs remained stable ( 0 or 1 cell), at both time-points. (Table 3 and Table S1). Between baseline and 6 months, the number of CTCs increased, decreased, or remained stable in $29.6 \%, 14.8 \%$ and $55.6 \%$ patients, respectively (Table 3 and Table S1). Finally, between 3 and 6 months of treatment, the number of CTCs increased, decreased, or remained stable in $42.9 \%, 23.8 \%$ and $33.3 \%$ of the patients, respectively (Table 3 and Table S1). As it was observed, 3 out of 6 months of treatment led to a decrease in the absolute number of CEACAM5-positive cells in a higher percentage of patients (37.7\% vs $14.8 \%$, respectively), whereas between 3 and 6 months resulted to significant increase in $42.9 \%$ of patients $(p=0.007$; Table 3 and Table S1).

Furthermore, CTC detection at baseline was more common in patients under 70s than those $\geq 70$ years old ( 44 vs. 11 patients; $p=0.006$ ). However, a higher number of patients $\geq 70$ and a lower number of $<70$ years old was demonstrated to decrease their CTCs between baseline and 3 months of treatment (22 vs. 4 patients; $p=0.033$ ) (Table S1). No other correlations were observed between patients' characteristics and CTC detection.

\subsubsection{Reverse Transcription-Quantitative PCR}

From the analysis of RT-qPCR results, it was observed that both the positivity of patients and CTCs copy numbers reduced between baseline and three months of treatment [38.3\%; median copy numbers: 1.1 (range: $0.71-6.7$ ) vs. $34.8 \%$; median copy numbers: 1.1 (range: 0.75-2.4]; whereas, an increase was observed again, after 6 months of treatment [42.6\%; median copy numbers: 1.2 (range: 0.71-12.33] (Table 2 and Table S1). It is worth mentioning that there was a statistically significant correlation of the results obtained between IFAT and RT-qPCR, at all time points $(p>0.001 ; p>0.001$ and $p>0.001$, respectively; Table 2). 
3.2.3. Association of Chemotherapy Regimen with Changes in the Absolute Number and Copy Number of CTCs during Treatment

By associating the regimen administered with the absolute number of CTCs detected by IFAT, it was revealed that patients under CAPOX decreased their detectable CTCs after three months, despite of not statistical significance ( $p=0.554$; Table 4 and Table S1). In the case of patients under FOLFOX, significantly increased CTCs were observed after administration of chemotherapy for 6 months ( $p=0.001$; Table 4 and Table S1). A significantly increased number of detectable CTCs was also observed between 3 and 6 months in patients under FOLFOX ( $p=0.05$; Table 4 and Table S1). Similarly, by associating the regimen administered with the copy numbers of CTCs detected by RT-qPCR, a significant increase in copy numbers was observed between baseline and 6 months $(p=0.011)$ and also between three and 6 months $(p=0.046)$ in patients under FOLFOX (Table S1).

Table 4. Comparison of absolute number of CTCs at each time point and chemotherapy regimen.

\begin{tabular}{|c|c|c|c|c|c|c|c|c|c|}
\hline & \multicolumn{3}{|c|}{ Baseline vs. 3 Months } & \multicolumn{3}{|c|}{ Baseline vs. 6 Months } & \multicolumn{3}{|c|}{3 Months vs. 6 Months } \\
\hline & Increase & Decrease & $p$ & Increase & Decrease & $p$ & Increase & Decrease & $p$ \\
\hline FOLFOX & $7(16.7 \%)$ & $9(21.4 \%)$ & 0554 & $13(54.2 \%)$ & $1(4.2 \%)$ & 0001 & $8(57.1 \%)$ & $2(14.3 \%)$ & 05 \\
\hline CAPOX & $9(21.4 \%)$ & $17(40.5 \%)$ & 0.554 & $3(12.5 \%)$ & $7(29.2 \%)$ & 0.001 & $1(7.1 \%)$ & $2(21.4 \%)$ & 0.05 \\
\hline
\end{tabular}

Furthermore, the association of the absolute CTCs detection number was investigated in patients under CAPOX for 3 months vs FOLFOX for 6 months. As it was demonstrated, $30.3 \%$ and $17 \%$ of the patients under CAPOX for 3 and FOLFOX for 6 months, respectively, had detectable CTCs. This was not of any statistical significance $(p=0.9)$, thus providing additional evidence of non-inferiority of 3 out of 6 months of treatment (Table S1). Additionally, as demonstrated in Figure 2, 10 (14.9\%) and 9 (13.4\%) patients under FOLFOX for 6 and CAPOX for 3 months, respectively, increased the number of their CTCs in their blood; whereas 1 (1.5\%) and 15 (22.4\%) patients under FOLFOX for 6 and CAPOX for 3 months, respectively, decreased their CTCs, and this is of a statistical significance $(p=0.004)$ (Figure 2 and Table S1).

\section{$30.0 \%$}

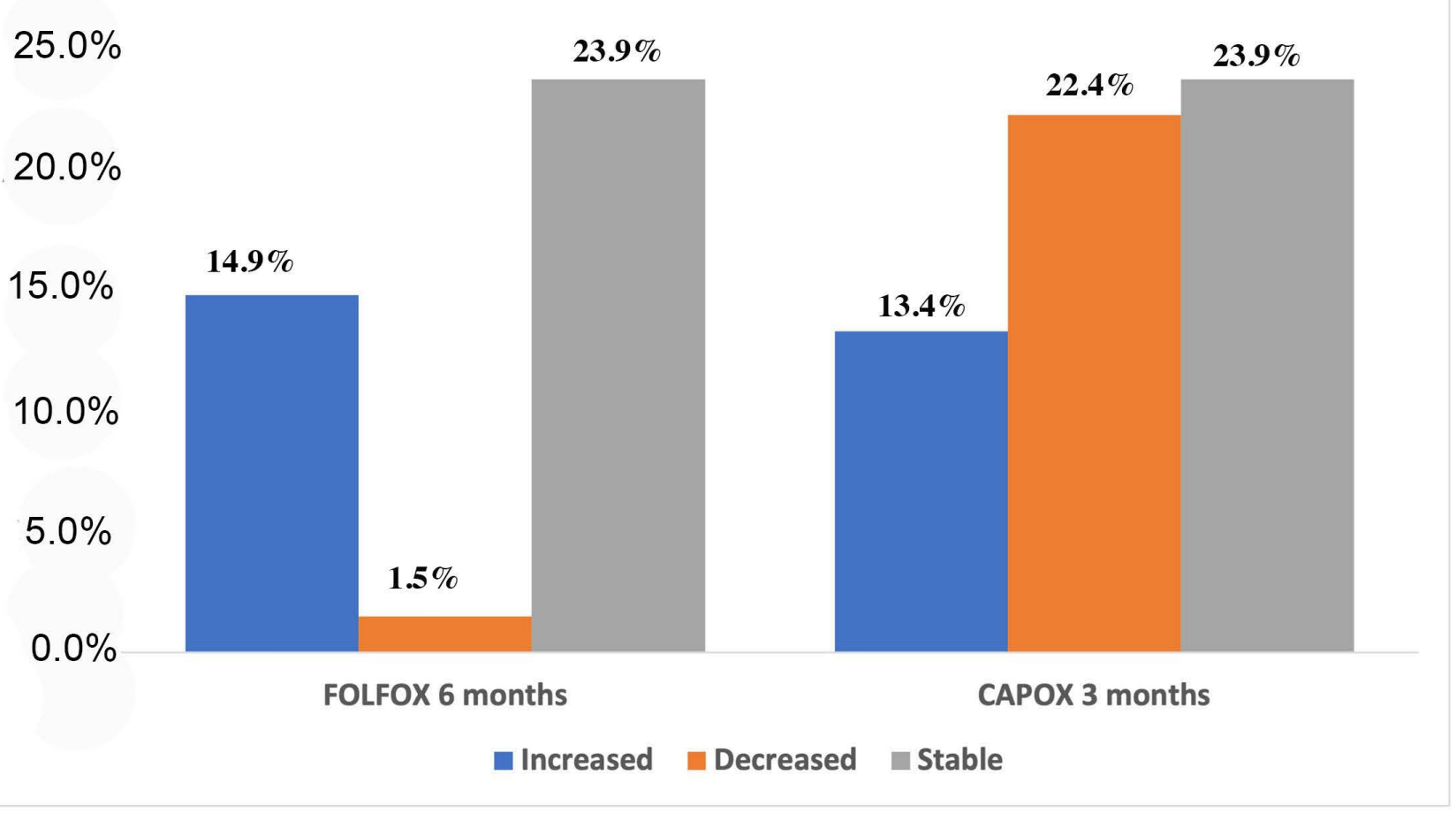

Figure 2. Rates (\%) of patients whose CTC number increased, decreased or remained stable during different treatment regimens (FOLFOX for 6 months vs CAPOX for 3 months). 


\subsection{Detection of Microbial DNA Fragments}

Detection of microbial DNA for 16S rRNA, E. coli, B. fragilis and 5.8S rRNA of C. albicans was detected in the blood of $52(43 \%), 26(21.5 \%), 37(30.6 \%)$ and $46(38 \%)$ stage III CRC patients at baseline (Figure 3 and Table S1).

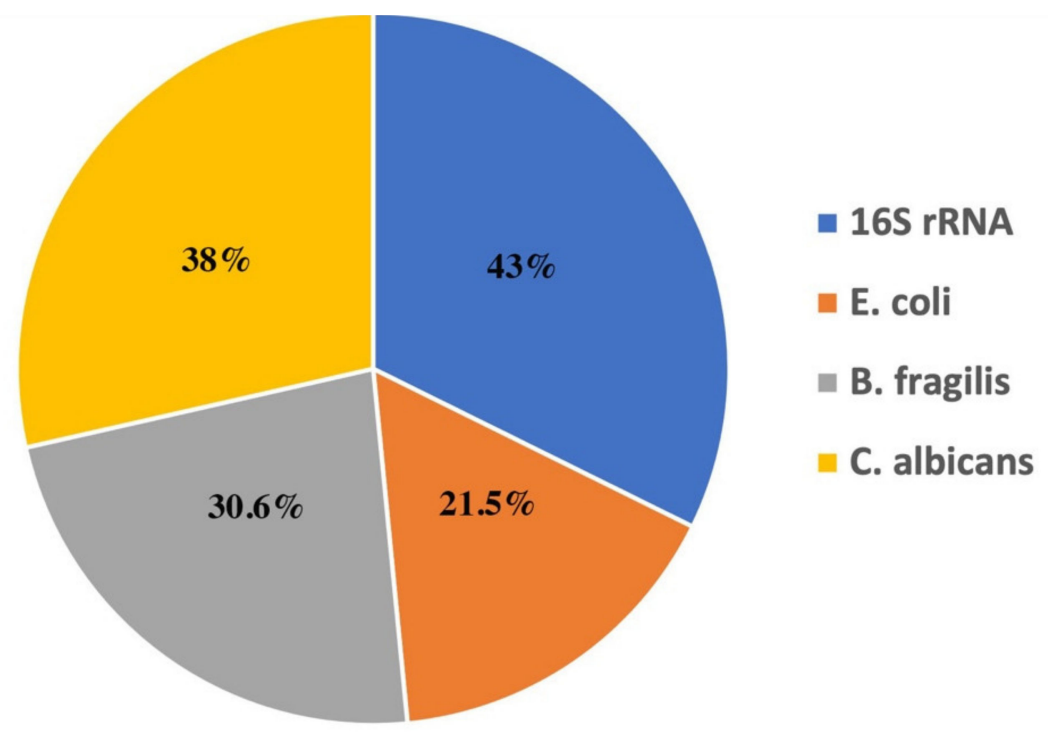

Figure 3. Detection rates (\%) of microbial DNA at baseline in stage III CRC patients.

A significant association was demonstrated with the CTC detection at baseline and all four microbial DNAs detected $(p=0.026, p=0.02, p<0.001$ and $p=0.029$ for 16S rRNA E. coli, B. fragilis and 5.8S rRNA of C. albicans, respectively; Table 5) when all patients were evaluated. Moreover, a statistically significant association was revealed between the detection of microbial DNA coding for $16 \mathrm{~S}$ rRNA and glutamine synthase gene of $B$. fragilis with the increase of CTCs number between baseline and three months of chemotherapy when all patients were evaluated (Table 5). When patients were grouped according to treatment regimen, it was demonstrated that patient under FOLFOX presented a significant association between baseline CTCs detection and E. coli $(p=0.036)$, baseline CTCs detection and B. fragilis $(p=0.01)$ and between the detection of microbial DNA coding for 16S rRNA and the increase of CTCs number between baseline and three months of chemotherapy $(p=0.034)$ (Table 5). Moreover, in patients under CAPOX, a significant association was demonstrated between baseline CTCs detection and B. fragilis $(p=0.015)$, baseline CTCs detection and 5.8S rRNA of $C$. albicans $(p=0.029), 3$ months CTCs detection and 16S rRNA $(p=0.043), 3$ months CTCs detection and B. fragilis $(p=0.013)$, and between the detection of microbial DNA coding for $16 \mathrm{~S}$ rRNA or $B$. fragilis and the increase of CTCs number between baseline and 3 months of chemotherapy ( $p=0.009$ and $p=0.015$, respectively) (Table 5). No other significant correlations were demonstrated with microbial DNA detection and patients' characteristics at any treatment regimen. 
Table 5. Association of microbial DNA detection at baseline with the detection of CTCs during treatment.

\begin{tabular}{|c|c|c|c|c|c|c|c|}
\hline & & \multicolumn{6}{|c|}{ CTCs Detection (All Treatments) } \\
\hline & & Baseline & 3 Months & 6 Months & $\begin{array}{l}\text { Increase between } \\
\text { Baseline-3 Months }\end{array}$ & $\begin{array}{l}\text { Increase between } \\
\text { Baseline-6 Months }\end{array}$ & $\begin{array}{c}\text { Increase between } \\
\text { 3-6 Months }\end{array}$ \\
\hline \multirow[b]{4}{*}{$\begin{array}{l}\text { Microbial } \\
\text { DNA }\end{array}$} & 16S rRNA & $p=0.026$ & $p=0.108$ & $p=0.799$ & $p=0.02$ & $p=0.108$ & $p=1$ \\
\hline & E. coli & $p=0.02$ & $p=0.921$ & $p=0.45$ & $p=0.462$ & $p=0.268$ & $p=0.789$ \\
\hline & B. fragilis & $p<0.001$ & $p=0.160$ & $p=0.887$ & $p=0.036$ & $p=0.163$ & $p=0.574$ \\
\hline & C. albicans & $p=0.029$ & $p=0.392$ & $p=0.257$ & $p=0.201$ & $p=0.11$ & $p=0.5$ \\
\hline \multirow[b]{6}{*}{$\begin{array}{l}\text { Microbial } \\
\text { DNA }\end{array}$} & & \multicolumn{6}{|c|}{ CTCs Detection (FOLFOX only) } \\
\hline & & Baseline & 3 months & 6 months & \multirow{5}{*}{$\begin{array}{c}\text { Increase between } \\
\text { Baseline-3 months } \\
\begin{array}{c}p=0.034 \\
p=0.538 \\
p=0508 \\
p=0.404\end{array}\end{array}$} & $\begin{array}{l}\text { Increase between } \\
\text { Baseline- } 6 \text { months }\end{array}$ & \multirow{5}{*}{$\begin{array}{c}\text { Increase between } \\
\text { 3-6 months } \\
p=1 \\
p=1 \\
p=0.667 \\
p=0.255\end{array}$} \\
\hline & 16S rRNA & $p=0.18$ & $p=0.279$ & $p=0.341$ & & $p=0.409$ & \\
\hline & E. coli & $p=0.036$ & $p=0.545$ & $p=0.295$ & & $p=0.469$ & \\
\hline & B. fragilis & $p=0.01$ & $p=0.643$ & $p=0.326$ & & $p=0.404$ & \\
\hline & C. albicans & $p=0.392$ & $p=0.383$ & $p=0.659$ & & $p=0.509$ & \\
\hline \multirow[b]{6}{*}{$\begin{array}{l}\text { Microbial } \\
\text { DNA }\end{array}$} & & \multicolumn{6}{|c|}{ CTCs Detection (CAPOX only) } \\
\hline & & Baseline & 3 months & 6 months & \multirow{4}{*}{$\begin{array}{l}\text { Increase between } \\
\text { Baseline-3 months } \\
\qquad \begin{array}{c}p=0.009 \\
p=0.293 \\
p=0.015\end{array}\end{array}$} & \multirow{4}{*}{$\begin{array}{l}\text { Increase between } \\
\text { Baseline-6 months } \\
\qquad \begin{array}{c}p=0.306 \\
p=0.236 \\
p=0.464\end{array}\end{array}$} & \multirow{4}{*}{ 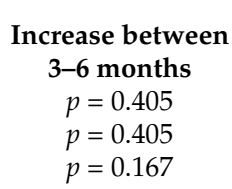 } \\
\hline & 16S rRNA & $p=0.137$ & $p=0.043$ & $p=0.392$ & & & \\
\hline & E. coli & $p=0.355$ & $p=0.384$ & $p=1$ & & & \\
\hline & B. fragilis & $p=0.013$ & $p=0.013$ & $p=1$ & & & \\
\hline & C. albicans & $p=0.029$ & $p=0.082$ & $p=0.76$ & $p=0.322$ & $p=0.094$ & $p=0.167$ \\
\hline
\end{tabular}

\section{Discussion}

CRC, at a large extent is preventable and curable disease [29]. Even, for stage III CRC adjuvant chemotherapy (FOLFOX or CAPOX) reduced disease recurrence risk and mortality by $30 \%$ and $32 \%$, respectively [2,3,30-32]. The gold standard use of oxaliplatin-based regimens for 6 months is usually accompanied with several adverse events. Neuropathy is the main problem for a number of patients. Neuropathy can be long lasting and have an impact on the patients' quality of life, often leading to treatment discontinuation [33]. The IDEA pooled analysis of six randomized trials, was the first attempt aiming to shorten the duration of adjuvant treatment [6]. The study did not achieve the expected statistical significance for shortening adjuvant treatment duration from 6 to 3 months, in CRC patients; however, there was a clear trend for patients with lower risk CRC (T1-T3/N1) to benefit from the administration of CAPOX for three months [6]. Although the interpretation of the IDEA's results was hard, it was revealed that tumor's special characteristics and patients' desires about quality of life may define regimen and treatment duration [5].

Liquid biopsy is a promising tool for tumor characterization [34] and CTCs detection in CRC patients has a prognostic and predictive value [12,14,15,35-37]. The aim of the study was to evaluate the detection and number of CTCs at baseline, after 3 (for all patients) and after 6 months of treatment administration (for patients under 6 months treatment) and correlate such evaluation with microbial DNA fragments in the blood of stage III CRC patients. Gut microbiota has been shown to be implicated in tumorigenesis and disease outcome. Microbial DNA fragments detection in patients with stage II/III or IV has already been demonstrated by our group, earlier [25].

To our knowledge, this is the first laboratory approach to evaluate the effect of 3 versus 6 months of adjuvant treatment, in stage III CRC patients. As it was shown, the rate of patients with detectable CTCs was nearly the same at all time points evaluated (IFAT: $44.4-45 \%$ and RT-qPCR: $34.8-42.6 \%$ ); The results of our study are in agreement with Sotelo et al., who demonstrated approximately the same positivity rates (IIIA: $40 \%$, IIIB: $32 \%$, IIIC: $47 \%$ ), despite the use of other detection methodologies [38]. Hoon Baek et al., demonstrated that a higher rate (84.1\%) of patients had detectable CTCs, preoperatively [39]. Dizdar et al., shown that 31.3-41.3\% CRC patients with no detectable metastases or with hepatic metastases, had detectable CTCs postoperatively, depending on methodology [40]. 
Recently, Hendricks et al., studied the rate of patients with detectable CTCs with three different methods: $\mathrm{NYONE}^{\mathrm{R}}$ cell imager, ScreenCell ${ }^{\mathrm{R}}$ and PCR [41]. The rates of positivity were: $36.4 \%, 100 \%$ and $80 \%$, respectively [41]. In the current study, significant changes were observed in the absolute number of CTCs. To this end, median number and range of CTCs presented a significant decrease after three months of adjuvant treatment, especially in patients under CAPOX. A significant increase in the absolute number of CTCs was demonstrated, especially in patients under FOLFOX. Therefore, both IFAT and RT-qPCR, revealed that 3 out of 6 months administration presented higher treatment efficacy. By a literature review, only studies on metastatic CRC and changes in positivity rate of CTCs during the treatment were demonstrated. Cohen et al., aimed to demonstrate the prognostic and predictive value of CTCs in patients with metastatic CRC. The authors showed that the number of patients with detectable CTCs decreases during treatment (from baseline to twenty weeks) [13]. Bidard et al., showed that in patients with potentially respectable metastatic CRC, there was an elimination of CTCs during preoperative treatment until resection (19\% at baseline, $3 \%$ at week 4 and $0 \%$ before surgery) [42].

Overall, it is reasonable to hypothesize that patients under adjuvant chemotherapy, longer than 3 months, might acquire resistant CEACAM5-positive CTC clones, leading to their accumulation after 6 months of treatment. However, to prove this hypothesis, extensive research is needed. Moreover, regarding microbial DNA fragments, the results of the present study, in stage III CRC patients are in agreement with the results presented earlier by Messaritakis et al., in early CRC patients (stage II/III) [25]. In brief, $43 \%, 21.5 \%$, $30.6 \%$ and $38 \%$ of stage III CRC patients had detectable microbial DNA for $16 \mathrm{~S}$ rRNA, E. coli, B. fragilis, and 5.8S rRNA in C. albicans, respectively. Messaritakis et al., demonstrated that $42.8 \%, 21.2 \%, 31.2 \%$ and $37 \%$ of stage II/III CRC patients had detectable microbial DNA for $16 \mathrm{~S}$ rRNA, E. coli, B. fragilis, and 5.8S rRNA in C. albicans, respectively. These rates were increased to $88.4 \%, 31.7 \%, 82 \%$ and $81 \%$ respectively, in stage IV CRC patients [25].

Finally, there was a significant correlation between the detection of all microbial DNAs evaluated and the detection of CEACAM5-positive cells at baseline, whereas a significant correlation was revealed between the detection of microbial DNA encoding for $16 \mathrm{~S}$ rRNA and glutamine synthase gene of $B$. fragilis, and the increase in CTCs after three months of treatment. A possible explanation of such correlation might be the delayed treatment response due to the presence of bacterial species [43-46]. As mentioned earlier, no statistical significance was demonstrated among the detection of any microbial DNA and the increase in CTC from baseline to 6 months, or from 3 to 6 months. A possible scenario for this might be again the acquired chemoresistance, which might determine treatment response beyond the period 3 months, thus displacing other factors (such as microbial components).

Extensive research is needed to evaluate whether such microbial DNA fragment detection which is possibly originated from the intestine was implicated in the treatment efficacy, or if potential intervention to microbial synthesis (remodeling) might boost treatment. On the other hand, the present is a non-randomized prospective study and carries all the limitations of a randomized trial and of a relatively small size study. For these reasons, the results should be interpreted with caution, and mainly as hypothesis generated. Further studies, longer patients' follow up and correlations with clinico-pathological features are needed, aiming to a personalized treatment decision, in the means of regimen and duration.

\section{Conclusions}

In conclusion, our study is the first laboratory attempt to compare two different oxaliplatin-based regimens administered as 3- or 6-months adjuvant chemotherapy, in stage III CRC patients. The detection of CTCs using IFAT is significantly correlated with RT-qPCR. The results provide additional evidence of non-inferiority of 3 versus 6 months of treatment, mainly in patients under CAPOX. On the other hand, an increase on the rate of patients with detectable CTCs and of the absolute CTC number was shown in patients under FOLFOX, for 6 months. Microbial DNA fragments that are possibly originated from the intestine, in the blood of stage III CRC patients is significantly correlated with the 
detection of CTCs, at baseline, as well as with the increase in the number of CTC, during the first three months of treatment administration. Finally, subsequent studies are needed to further evaluate possible resistance mechanisms and emergence of resistant clones, in stage III patients under oxaliplatin-based treatments.

Supplementary Materials: The following are available online at https:/ /www.mdpi.com/article/10 .3390 / cancers13143552/s1, Table S1: Raw data material.

Author Contributions: Conceptualization, J.S.; methodology, I.M., A.K., E.T. and M.S.; validation, I.M., M.S. and M.T.; data curation I.M., A.K., M.C., N.G., J.T., D.M., M.T. and J.S.; formal analysis, I.M.; supervision, I.M. and J.S.; writing-original draft preparation, A.K. and I.M.; writing—review and editing, I.M. and J.S. All authors have read and agreed to the published version of the manuscript.

Funding: This work was fully supported by research grants from the Hellenic Society of Medical Oncology (HeSMO) and the GastoIntestinal Cancer Study Group (GIC-SG). The funders had no role in the design of the study, in the collection, analysis or interpretation of data, in the writing of the manuscript or in the decision to publish the results.

Institutional Review Board Statement: The study has been approved by the Ethics Committee/Institutional Review Board of the University Hospital of Heraklion (Number 7302/19-8-2009), and all patients signed a written informed consent form for their participation. All procedures performed were in accordance with the ethical standards of the institutional and/or national research committee and the 1964 Helsinki declaration, and its later amendments or comparable ethical standards.

Informed Consent Statement: Informed consent was obtained from all subjects involved in the study.

Data Availability Statement: The data presented in this study are available as a Supplementary Materials here, Table S1.

Conflicts of Interest: The authors declare no conflict of interest.

\section{References}

1. Torre, L.A.; Siegel, R.L.; Ward, E.M.; Jemal, A. Global Cancer Incidence and Mortality Rates and Trends-An Update. Cancer Epidemiol. Biomark. Prev. 2016, 25, 16-27. [CrossRef]

2. Andre, T.; Boni, C.; Navarro, M.; Tabernero, J.; Hickish, T.; Topham, C.; Bonetti, A.; Clingan, P.; Bridgewater, J.; Rivera, F.; et al. Improved overall survival with oxaliplatin, fluorouracil, and leucovorin as adjuvant treatment in stage II or III colon cancer in the MOSAIC trial. J. Clin. Oncol. 2009, 27, 3109-3116. [CrossRef] [PubMed]

3. Haller, D.G.; Tabernero, J.; Maroun, J.; de Braud, F.; Price, T.; Van Cutsem, E.; Hill, M.; Gilberg, F.; Rittweger, K.; Schmoll, H.J. Capecitabine plus oxaliplatin compared with fluorouracil and folinic acid as adjuvant therapy for stage III colon cancer. J. Clin. Oncol. 2011, 29, 1465-1471. [CrossRef]

4. Sobrero, A.; Douillard, J.Y. Reply to the letter to the editor: 'The hard road to patient-centered care: 3 or 6 months of adjuvant chemotherapy for patients with stage III colon cancer?' By P. Trendsz et al. Ann. Oncol. 2018, 29, 1883-1884. [CrossRef]

5. Sobrero, A.; Grothey, A.; Iveson, T.; Labianca, R.; Yoshino, T.; Taieb, J.; Maughan, T.; Buyse, M.; Andre, T.; Meyerhardt, J.; et al. The hard road to data interpretation: 3 or 6 months of adjuvant chemotherapy for patients with stage III colon cancer? Ann. Oncol. 2018, 29, 1099-1107. [CrossRef]

6. Grothey, A.; Sobrero, A.F.; Shields, A.F.; Yoshino, T.; Paul, J.; Taieb, J.; Souglakos, J.; Shi, Q.; Kerr, R.; Labianca, R.; et al. Duration of Adjuvant Chemotherapy for Stage III Colon Cancer. N. Engl. J. Med. 2018, 378, 1177-1188. [CrossRef]

7. Souglakos, J.; Boukovinas, I.; Kakolyris, S.; Xynogalos, S.; Ziras, N.; Athanasiadis, A.; Androulakis, N.; Christopoulou, A.; Vaslamatzis, M.; Ardavanis, A.; et al. Three- versus six-month adjuvant FOLFOX or CAPOX for high-risk stage II and stage III colon cancer patients: The efficacy results of Hellenic Oncology Research Group (HORG) participation to the International Duration Evaluation of Adjuvant Chemotherapy (IDEA) project. Ann. Oncol. 2019, 30, 1304-1310. [CrossRef] [PubMed]

8. Andre, T.; Meyerhardt, J.; Iveson, T.; Sobrero, A.; Yoshino, T.; Souglakos, I.; Grothey, A.; Niedzwiecki, D.; Saunders, M.; Labianca, R.; et al. Effect of duration of adjuvant chemotherapy for patients with stage III colon cancer (IDEA collaboration): Final results from a prospective, pooled analysis of six randomised, phase 3 trials. Lancet Oncol. 2020, 21, 1620-1629. [CrossRef]

9. Jia, S.; Zhang, R.; Li, Z.; Li, J. Clinical and biological significance of circulating tumor cells, circulating tumor DNA, and exosomes as biomarkers in colorectal cancer. Oncotarget 2017, 8, 55632-55645. [CrossRef] [PubMed]

10. Massague, J.; Obenauf, A.C. Metastatic colonization by circulating tumour cells. Nature 2016, 529, 298-306. [CrossRef] [PubMed]

11. Alix-Panabieres, C.; Pantel, K. Challenges in circulating tumour cell research. Nat. Rev. Cancer 2014, 14, 623-631. [CrossRef] 
12. Vardakis, N.; Messaritakis, I.; Papadaki, C.; Agoglossakis, G.; Sfakianaki, M.; Saridaki, Z.; Apostolaki, S.; Koutroubakis, I.; Perraki, M.; Hatzidaki, D.; et al. Prognostic significance of the detection of peripheral blood CEACAM5mRNA-positive cells by real-time polymerase chain reaction in operable colorectal cancer. Clin. Cancer Res. 2011, 17, 165-173. [CrossRef]

13. Cohen, S.J.; Punt, C.J.; Iannotti, N.; Saidman, B.H.; Sabbath, K.D.; Gabrail, N.Y.; Picus, J.; Morse, M.; Mitchell, E.; Miller, M.C.; et al. Relationship of circulating tumor cells to tumor response, progression-free survival, and overall survival in patients with metastatic colorectal cancer. J. Clin. Oncol. 2008, 26, 3213-3221. [CrossRef]

14. Messaritakis, I.; Sfakianaki, M.; Papadaki, C.; Koulouridi, A.; Vardakis, N.; Koinis, F.; Hatzidaki, D.; Georgoulia, N.; Kladi, A.; Kotsakis, A.; et al. Prognostic significance of CEACAM5mRNA-positive circulating tumor cells in patients with metastatic colorectal cancer. Cancer Chemother. Pharmacol. 2018, 82, 767-775. [CrossRef]

15. Huang, X.; Gao, P.; Song, Y.; Sun, J.; Chen, X.; Zhao, J.; Liu, J.; Xu, H.; Wang, Z. Relationship between circulating tumor cells and tumor response in colorectal cancer patients treated with chemotherapy: A meta-analysis. BMC Cancer 2014, 14, 976. [CrossRef] [PubMed]

16. Bleday, R.; Song, J.; Walker, E.S.; Salcedo, B.F.; Thomas, P.; Wilson, R.E.; Chen, L.B.; Steele, G., Jr. Characterization of a new monoclonal antibody to a cell surface antigen on colorectal cancer and fetal gut tissues. Cancer 1986, 57, 433-440. [CrossRef]

17. Tiernan, J.P.; Perry, S.L.; Verghese, E.T.; West, N.P.; Yeluri, S.; Jayne, D.G.; Hughes, T.A. Carcinoembryonic antigen is the preferred biomarker for in vivo colorectal cancer targeting. Br. J. Cancer 2013, 108, 662-667. [CrossRef]

18. Milaki, G.; Messaritakis, I.; Koinis, F.; Kotsakis, A.; Apostolaki, S.; Dermitzaki, E.K.; Perraki, M.; Hatzidaki, D.; Georgoulias, V. Prognostic value of chemotherapy-resistant CK19mRNA-positive circulating tumor cells in patients with advanced/metastatic non-small cell lung cancer. Cancer Chemother. Pharmacol. 2017, 80, 101-108. [CrossRef]

19. Cho, I.; Blaser, M.J. The human microbiome: At the interface of health and disease. Nat. Rev. Genet. 2012, 13, 260-270. [CrossRef]

20. Arroyo, V.; Moreau, R.; Kamath, P.S.; Jalan, R.; Gines, P.; Nevens, F.; Fernandez, J.; To, U.; Garcia-Tsao, G.; Schnabl, B. Acute-onchronic liver failure in cirrhosis. Nat. Rev. Dis. Primers 2016, 2, 16041. [CrossRef] [PubMed]

21. Kane, T.D.; Alexander, J.W.; Johannigman, J.A. The detection of microbial DNA in the blood: A sensitive method for diagnosing bacteremia and/or bacterial translocation in surgical patients. Ann. Surg. 1998, 227, 1-9. [CrossRef]

22. Barriere, S.L.; Lowry, S.F. An overview of mortality risk prediction in sepsis. Crit. Care Med. 1995, 23, 376-393. [CrossRef]

23. Bruns, T.; Reuken, P.A.; Stengel, S.; Gerber, L.; Appenrodt, B.; Schade, J.H.; Lammert, F.; Zeuzem, S.; Stallmach, A. The prognostic significance of bacterial DNA in patients with decompensated cirrhosis and suspected infection. Liver Int. 2016, 36, 1133-1142. [CrossRef]

24. Merlini, E.; Bellistri, G.M.; Tincati, C.; d'Arminio Monforte, A.; Marchetti, G. Sequencing of bacterial microflora in peripheral blood: Our experience with HIV-infected patients. J. Vis. Exp. 2011, e2830. [CrossRef]

25. Messaritakis, I.; Vogiatzoglou, K.; Tsantaki, K.; Ntretaki, A.; Sfakianaki, M.; Koulouridi, A.; Tsiaoussis, J.; Mavroudis, D.; Souglakos, J. The Prognostic Value of the Detection of Microbial Translocation in the Blood of Colorectal Cancer Patients. Cancers 2020, 12, 1058. [CrossRef]

26. Kallergi, G.; Papadaki, M.A.; Politaki, E.; Mavroudis, D.; Georgoulias, V.; Agelaki, S. Epithelial to mesenchymal transition markers expressed in circulating tumour cells of early and metastatic breast cancer patients. Breast Cancer Res. 2011, 13, R59. [CrossRef]

27. Papadaki, M.A.; Kallergi, G.; Zafeiriou, Z.; Manouras, L.; Theodoropoulos, P.A.; Mavroudis, D.; Georgoulias, V.; Agelaki, S. Co-expression of putative stemness and epithelial-to-mesenchymal transition markers on single circulating tumour cells from patients with early and metastatic breast cancer. BMC Cancer 2014, 14, 651. [CrossRef] [PubMed]

28. Messaritakis, I.; Stogiannitsi, M.; Koulouridi, A.; Sfakianaki, M.; Voutsina, A.; Sotiriou, A.; Athanasakis, E.; Xynos, E.; Mavroudis, D.; Tzardi, M.; et al. Evaluation of the detection of Toll-like receptors (TLRs) in cancer development and progression in patients with colorectal cancer. PLoS ONE 2018, 13, e0197327. [CrossRef] [PubMed]

29. Brenner, H.; Chen, C. The colorectal cancer epidemic: Challenges and opportunities for primary, secondary and tertiary prevention. Br. J. Cancer 2018, 119, 785-792. [CrossRef] [PubMed]

30. Andre, T.; Boni, C.; Mounedji-Boudiaf, L.; Navarro, M.; Tabernero, J.; Hickish, T.; Topham, C.; Zaninelli, M.; Clingan, P.; Bridgewater, J.; et al. Oxaliplatin, fluorouracil, and leucovorin as adjuvant treatment for colon cancer. N. Engl. J. Med. 2004, 350, 2343-2351. [CrossRef] [PubMed]

31. Kuebler, J.P.; Wieand, H.S.; O'Connell, M.J.; Smith, R.E.; Colangelo, L.H.; Yothers, G.; Petrelli, N.J.; Findlay, M.P.; Seay, T.E.; Atkins, J.N.; et al. Oxaliplatin combined with weekly bolus fluorouracil and leucovorin as surgical adjuvant chemotherapy for stage II and III colon cancer: Results from NSABP C-07. J. Clin. Oncol 2007, 25, 2198-2204. [CrossRef] [PubMed]

32. Andre, T.; de Gramont, A.; Vernerey, D.; Chibaudel, B.; Bonnetain, F.; Tijeras-Raballand, A.; Scriva, A.; Hickish, T.; Tabernero, J.; Van Laethem, J.L.; et al. Adjuvant Fluorouracil, Leucovorin, and Oxaliplatin in Stage II to III Colon Cancer: Updated 10-Year Survival and Outcomes According to BRAF Mutation and Mismatch Repair Status of the MOSAIC Study. J. Clin. Oncol. 2015, 33, 4176-4187. [CrossRef]

33. Grothey, A. Oxaliplatin-safety profile: Neurotoxicity. Semin. Oncol. 2003, 30, 5-13. [CrossRef]

34. Ding, Y.; Li, W.; Wang, K.; Xu, C.; Hao, M.; Ding, L. Perspectives of the Application of Liquid Biopsy in Colorectal Cancer. Biomed. Res. Int 2020, 2020, 6843180. [CrossRef] [PubMed]

35. Yang, C.; Zou, K.; Zheng, L.; Xiong, B. Prognostic and clinicopathological significance of circulating tumor cells detected by RT-PCR in non-metastatic colorectal cancer: A meta-analysis and systematic review. BMC Cancer 2017, 17, 725. [CrossRef] [PubMed] 
36. Cabel, L.; Proudhon, C.; Gortais, H.; Loirat, D.; Coussy, F.; Pierga, J.Y.; Bidard, F.C. Circulating tumor cells: Clinical validity and utility. Int. J. Clin. Oncol. 2017, 22, 421-430. [CrossRef] [PubMed]

37. Nanduri, L.K.; Hissa, B.; Weitz, J.; Scholch, S.; Bork, U. The prognostic role of circulating tumor cells in colorectal cancer. Expert Rev. Anticancer Ther 2019, 19, 1077-1088. [CrossRef]

38. Sotelo, M.J.; Sastre, J.; Maestro, M.L.; Veganzones, S.; Vieitez, J.M.; Alonso, V.; Gravalos, C.; Escudero, P.; Vera, R.; Aranda, E.; et al. Role of circulating tumor cells as prognostic marker in resected stage III colorectal cancer. Ann. Oncol. 2015, 26, 535-541. [CrossRef] [PubMed]

39. Baek, D.H.; Kim, G.H.; Song, G.A.; Han, I.S.; Park, E.Y.; Kim, H.S.; Jo, H.J.; Ko, S.H.; Park, D.Y.; Cho, Y.K. Clinical Potential of Circulating Tumor Cells in Colorectal Cancer: A Prospective Study. Clin. Transl. Gastroenterol. 2019, 10, e00055. [CrossRef]

40. Dizdar, L.; Fluegen, G.; van Dalum, G.; Honisch, E.; Neves, R.P.; Niederacher, D.; Neubauer, H.; Fehm, T.; Rehders, A.; Krieg, A.; et al. Detection of circulating tumor cells in colorectal cancer patients using the GILUPI CellCollector: Results from a prospective, single-center study. Mol. Oncol. 2019, 13, 1548-1558. [CrossRef]

41. Hendricks, A.; Brandt, B.; Geisen, R.; Dall, K.; Roder, C.; Schafmayer, C.; Becker, T.; Hinz, S.; Sebens, S. Isolation and Enumeration of CTC in Colorectal Cancer Patients: Introduction of a Novel Cell Imaging Approach and Comparison to Cellular and Molecular Detection Techniques. Cancers 2020, 12, 2643. [CrossRef]

42. Bidard, F.C.; Kiavue, N.; Ychou, M.; Cabel, L.; Stern, M.H.; Madic, J.; Saliou, A.; Rampanou, A.; Decraene, C.; Bouche, O.; et al. Circulating Tumor Cells and Circulating Tumor DNA Detection in Potentially Resectable Metastatic Colorectal Cancer: A Prospective Ancillary Study to the Unicancer Prodige-14 Trial. Cells 2019, 8, 516. [CrossRef]

43. Iida, N.; Dzutsev, A.; Stewart, C.A.; Smith, L.; Bouladoux, N.; Weingarten, R.A.; Molina, D.A.; Salcedo, R.; Back, T.; Cramer, S.; et al. Commensal bacteria control cancer response to therapy by modulating the tumor microenvironment. Science 2013, 342, 967-970. [CrossRef] [PubMed]

44. Lin, C.; Cai, X.; Zhang, J.; Wang, W.; Sheng, Q.; Hua, H.; Zhou, X. Role of Gut Microbiota in the Development and Treatment of Colorectal Cancer. Digestion 2019, 100, 72-78. [CrossRef]

45. Wong, S.H.; Yu, J. Gut microbiota in colorectal cancer: Mechanisms of action and clinical applications. Nat. Rev. Gastroenterol. Hepatol. 2019, 16, 690-704. [CrossRef] [PubMed]

46. Yu, T.; Guo, F.; Yu, Y.; Sun, T.; Ma, D.; Han, J.; Qian, Y.; Kryczek, I.; Sun, D.; Nagarsheth, N.; et al. Fusobacterium nucleatum Promotes Chemoresistance to Colorectal Cancer by Modulating Autophagy. Cell 2017, 170, 548-563. [CrossRef] [PubMed] 